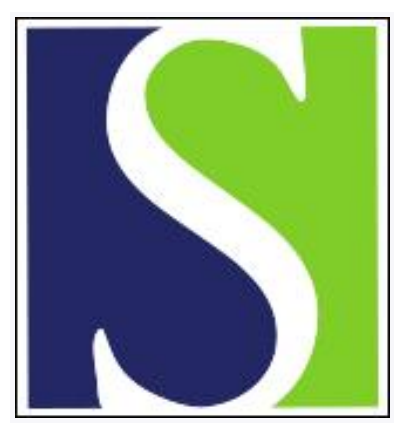

Scand J Work Environ Health 1983;9(5):391-396

https://doi.org/10.5271/sjweh.2395

Issue date: Oct 1983

Effects of trace levels of nitrous oxide on psychomotor performance.

by Venables H, Cherry N, Waldron HA, Buck L, Edling C, Wilson HK

This article in PubMed: www.ncbi.nlm.nih.gov/pubmed/6673097

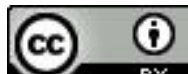




\title{
Effects of trace levels of nitrous oxide on psychomotor performance
}

\author{
by Helen Venables, BSc, ${ }^{1}$ Nicola Cherry, PhD, ${ }^{1}$ Harry A Waldron, MD, ${ }^{1}$ \\ Leslie Buck, $\mathrm{PhD},{ }^{2}$ Christer Edling, MD, ${ }^{3}$ Hugh $\mathrm{K}$ Wilson, $\mathrm{PhD}^{4}$
}

\begin{abstract}
VENABLES H, CHERRY N, WALDRON HA, BUCK L, EDLING C, WILSON HK. Effects of trace levels of nitrous oxide on psychomotor performance. Scand $j$ work environ health 9 (1983) 391-396. Twenty-four male student volunteers were exposed to $50 \mathrm{ppm}$ of nitrous oxide or air in an exposure chamber for $4 \mathrm{~h}$ in two experimental sessions. The subjects completed a battery of psychomotor tests during the final 40 min of the exposure sessions. Nitrous oxide, at this low concentration, did not produce any statistically significant changes in performance.
\end{abstract}

Key terms: audiovisual test, exposure chamber, psychometric tests.

During the last ten years, several studies have shown different health hazards for operating theater personnel (10). In the setting of hygienic standards or other hygiene control limits, the level at which nitrous oxide causes a decrement in performance has been the subject of much debate. High levels of nitrous oxide, $20 \%$ and above, cause a deterioration on tests of reaction time $(9,13)$. After exposing volunteers to a range of concentrations, Allinson et al (2) concluded that the threshold at which nitrous oxide started to affect performance lay between 8 and $12 \%$.

Controversy exists over the effects, if any, of trace levels of anesthetic gases on performance. Gamberale \& Svensson (12) and Snyder et al (15) found no acute behavioral effects of trace levels of anesthetic

1 TUC Centenary Institute of Occupational Health, Lond on School of Hygiene \& Tropical Medicine, London, United Kingdom.

2 National Research Council, Division of Mechanical Engineering, Ottawa, Canada K1A OR6.

3 Department of Occupational Health, University Hospital, Linköping, Sweden.

4 Occupational Medicine and Hygiene Laboratories, Health and Safety Executive, London, United Kingdom.

Reprint requests to: Dr HA Waldron, TUC Centenary Institute of Occupational Health, London School of Hygiene \& Tropical Medicine, Keppel Street (Gower Street), London WC1E 7HT, UK. gases on theater personnel. Bruce et al (5) and Bruce \& Bach (3), on the other hand, found that $500 \mathrm{ppm}(0.05 \%)$ affected performance on the digit-span test for shortterm memory. In a later study the same authors (4) found that $50 \mathrm{ppm}(0.005 \%)$ of nitrous oxide caused a deterioration in the performance of an audiovisual task and that $500 \mathrm{ppm}$ also caused a deterioration in the performance of vigilance and tachistoscopic tasks and the digit-span test. It is of interest to note that, in their earlier studies, these authors did not find any effect of $500 \mathrm{ppm}$ of nitrous oxide on the performance of an almost identical task. Other studies $(11,14)$ have failed to replicate the results of Bruce \& Bach (4) using a test battery which included an audiovisual task very similar to that used by Bruce et al (5).

Hygienic standards and control limits for the level of nitrous oxide in operating threaters have recently been set at new low values in several countries $(100 \mathrm{ppm}$ in Denmark, Norway and Sweden, $5 \mathrm{ppm}$ in Yugoslavia). These levels have apparently been based on Bruce \& Bach's findings (4), despite the failure of others to replicate them. The aim of the experiment reported in the present communication was to substantiate whether or not $50 \mathrm{ppm}$ of nitrous oxide causes a deterioration in psychomotor performance with an audio- 
visual task similar to that used by Bruce \& Bach (4). A short battery of other tests was also included.

\section{Methods}

\section{Subjects}

Twenty-four undergraduate and postgraduate students (mean age 25.2 years) were the subjects of this experiment. All of the subjects were in good health, and none of them were taking any drugs.

\section{Treatments}

Each subject received a placebo or $50 \mathrm{ppm}$ of nitrous oxide, in a design balanced for order effects, over two experimental sessions in an exposure chamber. The sessions were $4 \mathrm{~h}$ in duration, and performance testing took place during the final $40 \mathrm{~min}$ in the chamber.

\section{Exposure chamber}

The volunteers were seated in a $2.5-\mathrm{m}^{3}$ chamber constructed from perspex sheet on a metal frame, with air passing from ceiling vents down to extraction vents below a perforated false floor. A supply of clean air $\left(50 \mathrm{~m}^{3} / \mathrm{h}\right.$ with temperature and humidity controlled at $23 \pm 0.5^{\circ} \mathrm{C}$ and $52 \pm$ $2 \%$, respectively) was introduced into the chamber. Nitrous oxide (medical grade) was fed into the air inlet duct through a regulator and adjusted to give $50 \pm 2 \mathrm{ppm}$. The concentration of nitrous oxide in the chamber was monitored continuously with a Miran $1 \mathrm{~A}$ infrared spectrophotometer.

Four subjects were in the chamber during each session. Each group of subjects was tested at the same time of day (morning or afternoon) and on the same day of the week for both sessions. The subjects were provided with orange juice but were not allowed to drink coffee in the chamber. At the conclusion of the experiment the subjects' assessment of whether or not they had been exposed showed no relation to the actual conditions; it seems reasonable to conclude that the experiment was unbiased by the subjects' awareness of exposure.

\section{Performance tests}

The subjects were fully briefed and trained to reach a plateau of performance on three of the four tests before the exposure sessions began. The audiovisual task was learned in the exposure chamber during the first exposure session. This procedure had to be used because of unexpected delays in the development of the test. For both sessions the subjects performed the four tests in the same order, the order of testing among the group of four subjects in the chamber being allocated according to a Latin square design.

Audiovisual task. This test was designed to replicate the task created by Bruce \& Bach (4) as closely as possible. The subject was presented simultaneously with an auditory and a visual stimulus. The visual stimulus was either a horizontal line or a sine wave presented on an oscilloscope. The auditory stimulus was either a slow clicking ( $120 \mathrm{clicks} / \mathrm{min})$ or a fast clicking (180 clicks/min) presented through headphones. Hence there were four combinations of stimuli: flat line, fast clicking; flat line, slow clicking; sine wave, slow clicking; sine wave, fast clicking. The combination of stimuli changed after $4.5 \mathrm{~s}$, the combinations being presented in a predetermined, but random sequence. The subject's task was to indicate as quickly as possible each time there was a change of stimulus combination by pressing the appropriate button on a response panel. The test period was $7.5 \mathrm{~min}$, during which 100 changes of stimulus combination took place, 25 each of the four combinations. There was an initial training period of 15 min during the first session in the chamber, and during the second session the subjects were given 7.5 min of practice on the task.

The time taken from the change of stimulus combination to the subject's pressing of the correct response button was measured for all 100 changes, and the overall mean reaction time was computed.

Simple reaction time. Simple reaction time was measured for $8 \mathrm{~min}$ with a modified cassette recorder designed by Wilkinson \& Houghton (17). The subject's task was to press a white button in response to a red light which appeared in a stimulus win- 
dow. In this experiment the test was modified so that the subject did not have feedback of his reaction time after each response. This situation was achieved by the placing of a frosted glass slide over the stimulus window. [For further details see the report of Cherry et al (7).] The mean reaction time was computed from the individual responses recorded.

Four-choice reaction time. The subjects also performed a four-choice reaction time test for $8 \mathrm{~min}$. The task is one of speeded repetitive decision making, and performance is measured on a piece of equipment similar to that used for measuring simple reaction time (16). The stimulus panel consists of four lights in a square configuration, the four response buttons being arranged in the same way beneath the lights. In order to extinguish the light, which is on, the subject has to press the response button which corresponds to it geometrically. If the wrong button is pressed, the light will still be extinguished, but an error response will be recorded. When a light has been extinguished, correctly or incorrectly, another or the same light will come on after $120 \mathrm{~ms}$ according to a random sequence.

The mean correct reaction time was computed together with two other variables, percentage of error responses and blocks (number of individual correct reaction times which were longer than $\mathbf{1 . 5}$ times the mean correct time).

Stressalyzer. The stressalyzer is a subjectpaced pursuit tracking task. [See the report of Buck et al (6) for a full account.] Several components of the subject's response on this task can be analyzed; these include reaction time, movement time, and errors. The subject has to align a pointer with one of five lights on a display. Accurate alignment causes the light to be extinguished and one of the other four to light up according to a random sequence.

A trial consists of a sequence of 100 stimuli and responses. During the exposure the subjects completed three trials after $2 \mathrm{~h}$ in the chamber and another three trials during the final testing session.

There were six variables for the stressalyzer: (i) correct reaction time, (ii) nonovershoot movement time, (iii) overshoot movement time, (iv) total reaction time, (v) errors, and (vi) overshoots.

\section{Visual analogue scales}

At the beginning and end of each exposure session the subjects were given visual analogue scales (18) on which to rate themselves along the dimensions of sleepiness, physical and mental tiredness, and general good health. The scales were lines, $10 \mathrm{~cm}$ in length, the ends of which were labeled as the two extremes of the dimensions. The subjects were instructed to put a cross on the line to indicate how they felt at that point in the exposure session.

The raw visual analogue scores were arc sin transformed (1), the difference between the scores at the beginning and the end of the exposure sessions forming the variable for analysis.

\section{Times of the exposure sessions}

The exposure sessions lasted $4 \mathrm{~h}$, which could be divided in to the following phases:

00.00 Subjects entered the chamber and completed the visual analogue scales.

02.00 Subjects performed three trials on the stressalyzer and spent $15 \mathrm{~min}$ training (first session) or $7.5 \mathrm{~min}$ (second session) on the audiovisual task.

03.20 Performance testing began.

04.00 Subjects completed the final visual analogue scales and left the chamber.

\section{Results}

One subject did not attend the session in which he would have received the placebo treatment. His results for the other session have been included in the analysis however.

\section{Mean scores on the performance tests}

Table 1 shows the mean performance scores on the four psychomotor tests at 
Table 1. Mean performance scores for 11 performance variables for 0 and $50 \mathrm{ppm}$ of nitrous oxide.

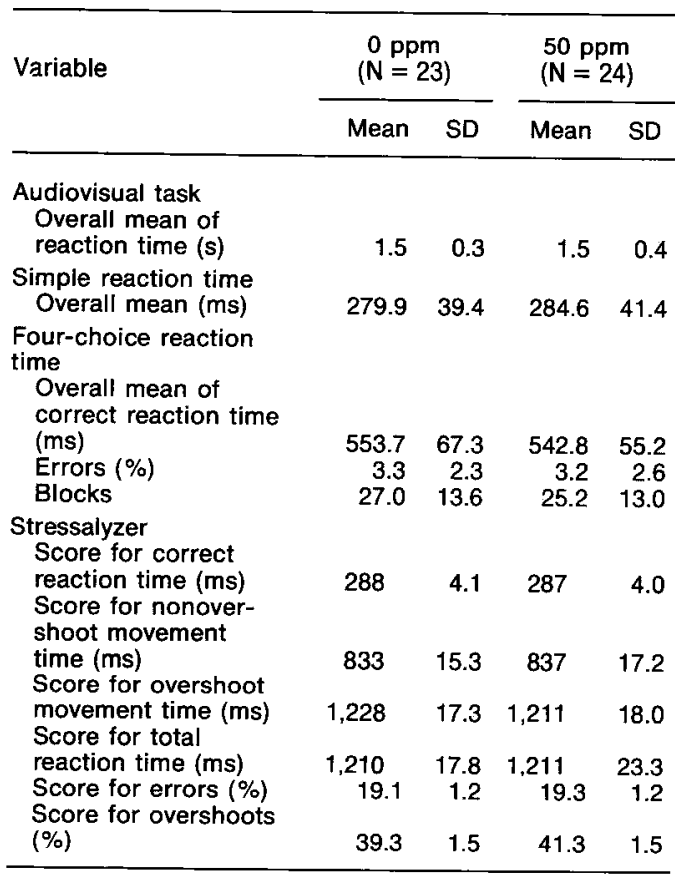

Table 2. Mean changes in the visual analogue scores for 0 and $50 \mathrm{ppm}$ of nitrous oxide. (A higher score indicates a greater deterioration over the exposure session.)

\begin{tabular}{lcccccc}
\hline \multirow{2}{*}{ Variable } & \multicolumn{2}{c}{$\begin{array}{c}0 \text { ppm } \\
(\mathbf{N}=23)\end{array}$} & & \multicolumn{2}{c}{$\begin{array}{c}50 \text { ppm } \\
(\mathbf{N}=23)\end{array}$} \\
\cline { 2 - 3 } \cline { 6 - 7 } & Mean & SD & & Mean & SD \\
& 27 & 59 & & 50 & 55 \\
& 17 & 51 & & 34 & 47 \\
Sleepiness & 22 & 54 & & 33 & 41 \\
Physical tiredness & 10 & 55 & & 17 & 28 \\
Mental tiredness & & & & & &
\end{tabular}

exposure levels of 0 and $50 \mathrm{ppm}$ of nitrous oxide. It is clear that there was no difference in performance between the two conditions. It is particularly worth noting that, in the case of the audiovisual task, the mean reaction time is exactly the same for both treatments.

\section{Visual analogue scores}

Table 2 shows the mean change in the visual analogue scores over the exposure sessions. It can be seen that there was a greater deterioration in mood on all four dimensions with exposure to $50 \mathrm{ppm}$ of nitrous oxide; the differences were not, however, statistically significant.

\section{Analysis of variance}

An analysis of variance was carried out for 11 performance variables. It was decided that nitrous oxide should be regarded as a fixed effect. The subjects were treated as though they were a random sample and entered into the analysis as a random effect.

The main effects of the subjects and the nitrous oxide and the twoway interactions between nitrous oxide $\times$ subjects were assessed, and the results are summarized in table 3 . Intersubject variation, which was tested against the residual variance, was statistically significant for all 11 performance variables. The effect of nitrous oxide, which was tested against the nitrous oxide $\times$ subjects interaction, was not statistically significant for any of the performance measures. The twoway interactions between nitrous oxide $\times$ subjects, which were tested against the residual variance, were significant for all the variables except overshoot movement time.

The error scores on the stressalyzer did not follow a normal distribution, and therefore differences in error scores between the two conditions were computed and subjected to a normal deviate test. The difference in error scores between the two conditions was not statistically significant $(t=0.58$, degrees of freedom 23).

\section{Discussion}

This experiment was set up in an attempt to replicate the influential report by Bruce \& Bach (4). This replication, using the audiovisual test described by Bruce \& Bach, was required since these authors $(3,5)$ had failed to find effects at exposure levels of $500 \mathrm{ppm}$ of nitrous oxide, using an almost identical test. A replication of Bruce \& Bach's positive results using the audiovisual test might have been important for the setting of standards for exposure in operating theaters. However the present results, taken together with Bruce \& Bach's earlier findings and those of Smith \& Shirley (14) and Frankhuizen 
Table 3. Summary table of the main effects of subjects and nitrous oxide and the twoway interactions between subjects $\times$ nitrous oxide for 11 performance variables. (NS $=$ not significant)

\begin{tabular}{|c|c|c|c|}
\hline \multirow[b]{2}{*}{ Variable } & \multicolumn{3}{|c|}{$\mathbf{F}$} \\
\hline & Subjects & $\begin{array}{l}\text { Nitrous oxide } \\
\times \text { subjects }\end{array}$ & $\begin{array}{l}\text { Nitrous oxide } \\
\text { (50 ppm) }\end{array}$ \\
\hline Audiovisual task & $6.8 p<.0 .001$ & $8.4 p<0.001$ & $0.1 \mathrm{NS}$ \\
\hline Simple reaction time & $21.9 p<0.001$ & $2.2 p<0.01$ & $0.8 \mathrm{NS}$ \\
\hline $\begin{array}{l}\text { Four-choice reaction time } \\
\text { Correct reaction time } \\
\text { Errors } \\
\text { Blocks }\end{array}$ & $\begin{array}{r}147.7 p<0.001 \\
25.7 p<0.001 \\
16.6 p<0.001\end{array}$ & $\begin{aligned} 13.1 p & <0.001 \\
2.3 p & <0.05 \\
2.5 p & <0.05\end{aligned}$ & $\begin{array}{l}1.7 \text { NS } \\
0.0 \text { NS } \\
0.9 \text { NS }\end{array}$ \\
\hline $\begin{array}{l}\text { Stressalyzer } \\
\text { Correct reaction time } \\
\text { Nonovershoot movement time } \\
\text { Overshoot movement time } \\
\text { Total reaction time } \\
\text { Overshoot }\end{array}$ & $\begin{aligned} 82.7 p<0.001 \\
201.9 p<0.001 \\
16.1 p<0.001 \\
40.2 p<0.001 \\
106.1 p<0.001\end{aligned}$ & $\begin{array}{l}5.1 p<0.001 \\
6.5 p<0.001 \\
1.2 \quad N S \\
2.8 p<0.05 \\
3.8 p<0.001\end{array}$ & $\begin{array}{l}0.1 \mathrm{NS} \\
0.1 \mathrm{NS} \\
2.1 \mathrm{NS} \\
0.0 \mathrm{NS} \\
1.8 \mathrm{NS}\end{array}$ \\
\hline Visual analogue scales & $8.9 p<0.001$ & $12.5 p<0.001$ & $1.2 \mathrm{NS}$ \\
\hline
\end{tabular}

et al (11), suggest that it is unlikely that trace levels of nitrous oxide produce a measurable deterioration in psychomotor performance.

Although we found no changes in performance in this experiment, the visual analogue scales showed a nonsignificant trend for mood to deteriorate more after $4 \mathrm{~h}$ of exposure to nitrous oxide than to air. This trend is similar to that consistently found for men exposed to low levels of organic solvents (8). As conditions of work improve and expectations increase, it may be that such changes in mood will have to be taken into account when hygienic standards and other hygiene control limits are set, even when performance is not affected.

\section{Acknowledgments}

We are very grateful to Ms P Ellis of the Health and Safety Executive Laboratory for her help in developing the version of the audiovisual task used in this experiment. The work was supported by grant 798/82 from the Swedish Work Environment Fund.

\section{References}

1. Aitken RCB. Measurement of feelings using visual analogue scales. Proc $r$ soc med 62 (1969) 989-993.

2. Allinson RH, Shirley AW, Smith G. Threshold concentration of nitrous oxide affecting psychomotor performance. $\mathrm{Br} \mathrm{j}$ anaesth 51
(1979) 177-180.

3. Bruce DL, Bach MJ. Psychological studies of human performance as affected by traces of enflurane and nitrous oxide. Anesthesiology 42 (1975) 194-205.

4. Bruce DL, Bach MJ. Effects of trace anaesthetic gases on behavioural performance of volunteers. $\mathrm{Br} \mathrm{j}$ anaesth 48 (1976) $871-876$.

5. Bruce DL, Bach MJ, Arbit J. Trace anesthetic effects on perceptual, cognitive and motor skills. Anesthesiology 40 (1974) $453-458$.

6. Buck L, Leonardo R, Hyde F. Measuring impaired performance with the NRC "stressalyser". Appl ergon 12 (1981) 231-236.

7. Cherry N, Venables $H$, Waldron HA. A test battery to measure the behavioural effects of neurotoxic substances. TUC Centenary Institute of Occupational Health, London 1982.

8. Cherry $N$, Venables $H$, Waldron HA. The acute behavioural effects of solvent exposure. J soc occup med 33 (1983) (1983) 13-18.

9. Cook TL, Smith M, Starkweather JA, Winter PM, Eger EI. Behavioural effects of trace and subanesthetic halothane and nitrous oxide in man. Anesthesiology 49 (1978) 419-424.

10. Edling C. Anaesthetic gases as an occupational hazard - A review. Scand $j$ work environ health 6 (1980) 85-93.

11. Frankhuizen JL, Vlek CAJ, Burm AGL, Rejger $V$. Failure to replicate negative effects of trace anesthetics on mental performance. $\mathrm{Br} \mathrm{j}$ anaesth 50 (1978) 229234.

12. Gamberale F, Svensson G. The effect of anesthetic gases on the psychomotor and perceptual functions of anesthetic nurses. Work environ health 11 (1974) 108-113.

13. Garfield JM, Garfield EB, Sampson J. Effects of nitrous oxide on decisionstrategy and sustained attention. Psychopharmacologia (Berlin) 42 (1975) 5-10. 
14. Smith G, Shirley AW. Failure to demonstrate effect of trace concentrations of nitrous oxide and halothane on psychomotor performance. $\mathrm{Br} \mathrm{j}$ anaesth 49 (1977) 65-70.

15. Snyder BD, Thomas RS, Gyorky $Z$. Behavioural toxicity of anesthetic gases. Ann neurol 3 (1978) 67-71.

16. Wilkinson RT, Houghton D. Portable fourchoice reaction time test with magnetic tape memory. Behav res methods instrum
7 (1975) $441-446$

17. Wilkinson RT, Houghton D. A portable machine for measuring simple reaction time. Hum factors 24 (1982) 487-493.

18. Zealley AK, Aitken RCB. Measurement of mood. Proc r soc med 62 (1969) 993-996.

Received for publication: 10 August 1983 